\title{
SUPPORTING CITIES' EMISSION MITIGATION STRATEGIES: MODELLING URBAN TRANSPORT IN A TIMES ENERGY SYSTEM MODELLING FRAMEWORK
}

\author{
JONAS FORSBERG \& ANNA KROOK-RIEKKOLA \\ Luleå University of Technology, Sweden
}

\begin{abstract}
The transport sector is a significant emitter of greenhouse gases (GHGs) and air pollutants in urban areas. How the transport sector evolve during the coming decades will have significant impact on the possibilities to meet tough climate and environmental targets. This makes transportation an important part of cities' Sustainable Energy and Climate Action Plans. Still, transportation is somewhat overlooked in many city-level analyses. Energy system optimisation models, like the TIMES modelling framework, are useful tools in identifying energy pathways to reach ambitious energy savings and emission mitigation targets. Based on the identification of urban transport-energy system characteristics, the needs of local governments, and insights from traditional transport models, we propose a partly new representation of the transport sector within a TIMES-City modelling framework, adapting it to the urban transport-energy setting to improve model realism and power of insight. TIMES-City supports analysis of intracity and long-distance passenger and freight transportation, including only the city organisation or the entire administrative city area. Detailed techno-economic-environmental representation of all major existing and emerging modes, technologies and fuels provides basis for consistent long-term analyses.

Keywords: energy system optimisation model, urban energy system, urban transports, transportenergy setting, TIMES-City, sustainable energy and climate action plan, sustainable urban mobility plans, local energy policy.
\end{abstract}

\section{INTRODUCTION}

The European Commission (EC) have highlighted cities as the drivers of the European economy, while also emphasizing the importance of well-functioning urban transportation to continue to attract investments and create jobs [1]. However, transportation also bring significant external effects. From a global perspective, emissions of greenhouse gases (GHGs) is top priority, and transportation accounts for more than $20 \%$ of energy-related carbon emissions [2], but locally, air pollutants, congestion, noise, and safety are as important [3]. These emissions are attributed to the currently dominant technologies and fossil fuels. Mitigating emissions calls for comprehensive city-level strategies, assessing feasible and effective measures within the entire spectrum of the avoid-shift-improve framework [4].

An operations research approach can be useful to help structure the problem, and identify the system environment, its resources, and decision-makers [5]. When approaching problems of systemic character, mathematical models can be powerful tools for 'mental experiments' aimed at exploring system dynamics in an uncertain future [6]. Hence, comprehensive energy system optimisation models (ESOM) can be useful for cities when identifying energy, climate, and clean air strategies.

In this study, a TIMES-based ESOM is adapted and applied to the urban scale. Focus is on the urban transport-energy setting, which is somewhat overlooked or neglected in many urban energy system studies. We attempt to fill this gap, and to further improve model realism by adopting insights and approaches from traditional transport models. 


\subsection{Purpose and structure of the paper}

The aim of this study is to apply a TIMES-City modelling framework to the urban transportenergy setting, and to increase model realism by adopting insights from traditional transport models. The TIMES-City model is a comprehensive energy system optimisation model (ESOM), based on the TIMES modelling framework, under development within the SURECITY project [7]. Here, the model is applied to the city of Malmö (Sweden), but the general modelling approach enables the model to be applied on any European city.

The paper is structured as follows: Section 2 outlines the modelling requirements. Section 3 identifies some existing approaches and common practices when modelling transportenergy systems. Section 4 describes the adapted transport sector representation of the TIMES-city model, and the model application to Malmö city. In Section 5, the main points of the paper are discussed and concluded.

\subsection{The TIMES model framework}

The Integrated MARKAL-EFOM System (TIMES) is an energy system model platform developed by the Energy Technology Systems Analysis Programme (ETSAP) of the International Energy Agency (IEA). It is a technology-rich, bottom-up, linear optimisation, economic model generator, which seeks to satisfy user-defined energy-service demand at minimum cost. The scope of the model also extends to the representation of environmental emissions and materials related to the energy system [8]. TIMES models generally have very complex structures as they include the entire energy system of a given region, country, or city, from imports and domestic production of energy resources, to secondary energy carriers, end-us technologies, and energy service demands of the entire economy [9].

\section{MODEL REQUIREMENTS}

Models can help in exploring different futures, and in widening perspectives when assessing different options under uncertainty. Modelling efforts need to consider both the characteristics of the system, its performance measures, and the needs of decision makers. In this section, some distinguishing system characteristics and challenges facing local governments, which has implications for model requirements, are outlined.

\subsection{System characteristics}

The transport sector is a major energy-user and source of emissions in all urban areas. Generally, transport energy-use and emissions are determined by (i) the total demand for transport services, (ii) the specific energy-use per person or unit of goods transported, and (iii) the emission factors of fuels [2]. The urban transport system is characterised by a higher frequency of trips than in rural areas, short average distances, and low average speeds, which has possible implications for mode choice, energy-use and emissions. It has been noted that the systemic characteristics of urban transportation (e.g. transport mode shares) are generally more important for overall energy-use and emission performance than the behaviour of individual consumers or specific technology efficiencies [10].

\subsection{Needs of local governments}

The question of how to enhance mobility while at the same time reduce congestion, accidents and air pollution is a common challenge to all major European cities. Across the European Union (EU), local governments are adopting action plans to address this, e.g. Sustainable 
Urban Mobility Plans (SUMP). The SUMP is intended to promote high-quality sustainable urban mobility and transports. The guidelines highlight accessibility, safety, air and noise pollutions, energy, and GHG emissions [11]. Improved target-setting is needed to aid evaluation and benchmarking, and novel policy packages need to be thoroughly assessed to increase SUMP impact [12].

Several of the objectives in the transport plans are also shared with the objective of energy policies, e.g. to lower air pollutions [13], while other challenges for transportation are mainly addressed in the energy and climate plans, e.g. lowering the emissions of GHGs. One such plan of growing importance among cities in Europe is the Sustainable Energy and Climate Action Plans (SECAP), previously known as SEAP, which is promoted by the Covenant of Mayors initiative (CoM). In the SECAP, all signatories must quantify energy-use and emissions for the specified base-year, and produce recurring implementation reports [14]. The SECAP includes actions for buildings and facilities, industries, transportation, and electricity and heat/cold production. For transportation, the guidebook strongly recommends signatories to include (as minimum) urban road transports, and urban rail transports (metro, light rails, local trains) [15]. Despite the rapid growth of adopted plans, there is lack of standardisation in defining and expressing targets, baseline years, units, and actions, and alignment between short/medium-term and long-term targets is often unclear, which hampers comparison between cities, and assessments of joint mitigation effects [16].

Local decision-makers typically struggle to assess interactions between different sectors, and different targets, over longer time-periods. Appropriate decision support tools need to provide guidance on cost-effective local policies and technologies, and the 'optimal' sequential deployment of various measures in a long-time perspective [17].

\subsection{Modelling implications}

To be successful in informing policies for local-scale energy systems, models should provide understanding of long-term system dynamics and policy impacts. Fully exploring the urban transport-energy system performance requires taking different avoid, shift, and improve measures related to (i)-(iii) (see Section 2.1) into account and assessing policies and actions in a consistent manner. By putting the urban transport setting in an energy system perspective, alignment between targets for different energy end-use sectors can be captured and assessed. This requires a consistent and detailed representation of all parts of the local energy system, including technologies, raw materials and resources, fuels, and emission factors. Current modelling tools and urban energy system studies only partly address this.

\section{MODELLING APPROACHES AND PRACTICES}

In this section, approaches and common practices for assessing urban energy flows, urban transportation and the urban transport-energy intersect, are outlined. By adapting insights from each approach, the model realism of TIMES-City can improve with respect to specific challenges of the urban transport-energy system.

\subsection{Urban energy systems modelling}

Future supply and demand for energy in urban areas is attracting interest of both local governments and the research community. This is a broad topic; urban energy system studies vary significantly in scope, approaches, and time-horizons. Here, focus is on energy system modelling efforts targeting the city-level over medium to long-term horizons. 
A comprehensive review of urban energy system studies [18] pinpoints three important features when modelling urban energy futures: assessing the combined processes from resource extraction to final energy-use; explicitly including supply and demand-sides; and considering the specific local context. The reviewed studies are categorised as technology design, building design, system design, urban climate, or policy assessment. Additionally, land-use and transport interaction (LUT) studies are also included. However, current practices, including a variety of different tools, generally seem too narrow and fails to capture system-wide effects and implications. Only (some) reviewed system design and policy assessment studies target the systemic characteristics, or assess city-level policy impacts.

Very few studies include detail analysis of urban transport energy-use and emissions. There is significant potential to move beyond single disciplinary approaches by applying more comprehensive tools, which would improve policy relevance from model outputs [18].

\subsection{Transport modelling}

Transport models are typically used to predict international, national, regional, or local transport volumes and traffic flows. Models can also be used to assess impacts from transport policies (e.g. pricing schemes) or infrastructure projects (e.g. wider roads, new railways, etc.). [19] Traditional transport models use the so-called four-step approach, which essentially breaks down the forecasting problem into four computational steps [20]. This was initially applied to passenger transports in the mid- $20^{\text {th }}$ century [21], but experts agree that it can be fruitfully applied to freight transport modelling as well [22]. Four-step models are calibrated and validated against a chosen base-year, using data from e.g. travel surveys, trip-diaries, statistical freight data or commodity flow surveys [19], [23].

There is a variety of distinguishing factors to consider when modelling passenger travel demand and freight transport demand respectively. Passenger transport models typically account for trip-purpose (e.g. work, business, education, shopping, leisure, etc.), mode choice (e.g. car, bus, train, etc.), route choice (e.g. use of roads, railways, etc.), and departure times (day of week, time of day) [20]. Freight transport models, on the other hand, typically consider quantities of different commodity groups (e.g. manufactured or mining products, construction material, products of agriculture, forestry, etc.), origin and destination of flows, and modal splits (road, rail, shipping) [22]. Transport models have also been further developed to adapt to new policy-issues, including e.g. the effects of land-use on transport demand (land-use and transport interaction models) [24], and representing the behaviours of individuals (activity-based approaches) [25] or firms (logistics behavioural modelling) [26].

The strength of traditional transport models is the ability to provide insight on future bymode transport demands, taking different trip-purposes or commodity groups into account. Transferring this to the energy system modelling realm can improve understanding of mode shift potentials, and generate more 'realistic' demand inputs.

\subsection{Common practices and applications of TIMES models}

TIMES models are typically applied to national or multi-regional scale, but in recent years interest have grown for also it to explore urban energy systems (see e.g. the INSMART Project [27]). The transport sector is explicitly included in the model framework, but the level of detail and technology richness is typically lower than for other elements of the energy system [28]. The body of work using TIMES models to specifically analyse transportation is also very limited. Common approaches include e.g. high-level analysis of carbon taxes on transportation [29], the effects and implications of extensive transport sector electrification 
[30], and the impacts of reducing overall demand for transports on fuel consumption, costs and mitigation potentials as demonstrated in e.g. Yang et al. [31].

There are a few studies applying TIMES models to local scales. In Comodi et al. [32], the transport sector is not analysed in any detail, and due to lack of detailed local data, transport sector representation is highly simplified. In Lind and Espegren [33] on the other hand, a more detailed representation is made, including an array of technologychoices for passenger and freight transportation by all modes. In addition, demand is varied for different scenarios, and mode-shift measures are accounted for in analyses, albeit exogenously. This study provides insights for the profound changes needed to decarbonise urban transports to reach ambitious overall mitigation targets, but other emissions as e.g. local air pollution is excluded from the analysis.

The strengths of the TIMES framework are carried forward to the TIMES-City model. But for transportation, typical level of detail is not sufficient to cope with the urban transportenergy system characteristics, and the model framework have not been extensively tested for the policy-challenges posed by local governments.

\section{MODELLING URBAN TRANSPORTATION IN TIMES-CITY}

The TIMES-City model covers both energy-supply and demand sectors of the urban setting. More specifically, the model includes five demand sectors: Transport; Residential; Commercial; Industry; and Energy-supply activities (electricity, district heating and other). In this section, the transport sector representation in TIMES-City, and the application of the model to Malmö city, are described in detail.

\subsection{TIMES-City model specifications}

TIMES-City includes all major existing and emerging transport modes, technologies and fuels. Besides intracity transportation, for totality, the model also includes long-distance transportation outside city borders, which is attributed to the specific city (e.g. business trips, vacation trips, international freight shipping, etc.). The modelling scope is flexible and can either include 'all' activities of the city - municipality, private firms and residents - or be limited to the activity of the municipality.

The emphasis is on improving model representation of intracity transportation, whereas long-distance transportation is treated in line with present national TIMES models (e.g. JRC EU-TIMES). Fig. 1 illustrate all modes and technologies included in the model, for intracity passenger and freight transportation, respectively. The use of a non-travelling mode (No-tra.) for passengers (e.g. e-meetings, e-shopping) enables analysis of future shifts away from physical travelling. Walking, bicycling, light electric vehicles (LEV), light rails and metro, and city ferries are assumed to only provide intracity transportation services, whereas other modes can also supply transportation outside city limits. For freight, low-emission options for inner-city goods deliveries, such as bicycles and LEVs, can only provide intracity transportation services. Light (LGV) and heavy goods vehicles (HGV) can provide transportation services both within and outside the city. In the model, all technologies and energy commodities are assigned techno-environmental-economic properties, and hence can be assessed in a consistent manner. Included energy commodities and air emissions are listed in Table 1. The future costs of technologies and technology-efficiencies are adopted from the JRC EU-TIMES model [28]. Base-year fuel costs are based on IEA statistics [34], and future fuel costs are adopted from the 2DS scenario of the IEA's Energy Technology Perspective [35]. 

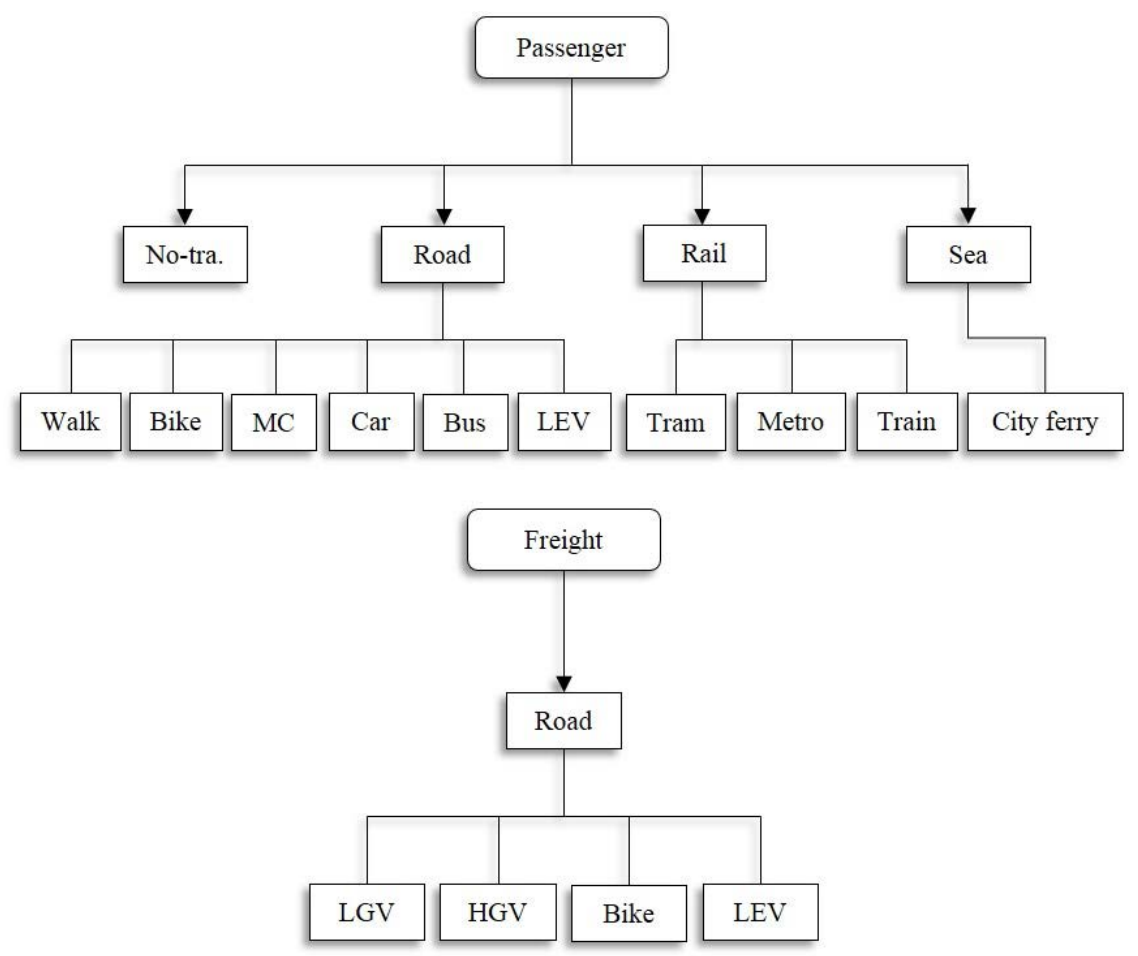

Figure 1: Modes and technologies covering intracity passenger and freight transportation. LEV=Light Electric Vehicle; LGV=Light Goods Vehicle; HGV=Heavy Goods Vehicle.

Table 1: Energy commodities and emissions included in TIMES-City.

\begin{tabular}{|c|c|c|}
\hline & Energy commodities & Emissions \\
\hline $\begin{array}{l}\text { Current and future } \\
\text { alternatives }\end{array}$ & $\begin{array}{l}\text { - Diesel } \\
\text { - Biodiesel } \\
\text { - Gasoline } \\
\text { - Bio-gasoline } \\
\text { - Ethanol } \\
\text { - Electricity } \\
\text { - Natural gas } \\
\text { - Biogas } \\
\text { - Liquified Petroleum Gas } \\
\text { (LPG) } \\
\text { - Methanol } \\
\text { - Dimethyl Ether (DME) } \\
\text { - Hydrogen }\end{array}$ & $\begin{array}{l}\text { - Carbon dioxide }\left(\mathrm{CO}_{2}\right) \\
\text { - Carbon monoxide }(\mathrm{CO}) \\
\text { - Methane }\left(\mathrm{CH}_{4}\right) \\
\text { - Sulphur dioxide }\left(\mathrm{SO}_{2}\right) \\
\text { - Nitrogen oxides }\left(\mathrm{NO}_{\mathrm{X}}\right) \\
\text { - Nitrous oxide }\left(\mathrm{N}_{2} \mathrm{O}\right) \\
\text { - Particulate matter }(\mathrm{PM} 2.5 \text {, } \\
\text { PM 10) } \\
\text { - Volatile Organic Compounds } \\
\text { (VOC) }\end{array}$ \\
\hline
\end{tabular}


Demand for person-km (pkm) or ton-km (tkm) are given as model input for each mode separately, disaggregated into intracity and long-distance (if applicable). All demand categories are listed in Table 2. Mode shifts are captured exogenously through pre-modelling analysis of data on trip purposes, mode choices, and trip distances (if available). This enables exploring e.g. specific mode share targets, or varying mode shares by trip purpose, which is then reflected in the pkm demand inputted to TIMES-City. Trip purposes are disaggregated into work, education, business, shopping, personal business, leisure, and other. The same approach can be used for freight, disaggregated by commodity groups as e.g. construction material, food and beverages, manufactured products, health care services, etc. Based on inputted demand, the TIMES model optimisation framework deploys the optimal mix of technologies and fuels to satisfy future demands for passenger and freight transportation at least cost.

\subsection{Applying TIMES-City to Malmö}

Application of TIMES-City is demonstrated for the transport-energy setting of Malmö city (Sweden). The focus is on intracity freight transports, and daily passenger trips (excl. vacation) within and from/into Malmö by city residents. Base-year data on passenger travel patterns are assumed equal to the results of Malmö city's 2013 travel survey [36]. No similar city-specific data on urban freight were identified, thus another approach is required (described below). Vehicle stock and annual mileage data was retrieved from Transport Analysis [37]. Additional data on the bus fleet was provided by the regional public transit authority (Skånetrafiken).

Table 2: By-mode demand categories in TIMES-City.

\begin{tabular}{|c|c|c|c|c|}
\hline \multirow{3}{*}{$\begin{array}{l}\text { By-mode } \\
\text { demands } \\
\text { Non-travelling }\end{array}$} & \multicolumn{4}{|c|}{ Transport sub-sector } \\
\hline & \multicolumn{2}{|c|}{ Passenger } & \multicolumn{2}{|c|}{ Freight } \\
\hline & Non-travelling & - & - & - \\
\hline \multirow{9}{*}{ Road } & Walk & Intracity & Bicycle & Intracity \\
\hline & Bicycle & Intracity & LEV & Intracity \\
\hline & LEV & Intracity & \multirow{2}{*}{ LGV } & Intracity \\
\hline & \multirow{2}{*}{$\mathrm{MC}$} & Intracity & & Long-dist. \\
\hline & & Long-dist. & $\mathrm{HGV}$ & Intracity \\
\hline & \multirow{2}{*}{ Car } & Intracity & HGV & Long-dist. \\
\hline & & Long-dist. & - & - \\
\hline & \multirow{2}{*}{ Bus } & Intracity & - & - \\
\hline & & Long-dist. & - & - \\
\hline \multirow{4}{*}{ Rail } & Light rail & Intracity & Freight train & Long-dist. \\
\hline & Metro & Intracity & - & - \\
\hline & \multirow{2}{*}{ Train } & Intracity & - & - \\
\hline & & Long-dist. & - & - \\
\hline \multirow{2}{*}{ Navigation } & City ferry & Intracity & Bunker & Long-dist. \\
\hline & Passenger ferry & Long-dist. & - & - \\
\hline \multirow{2}{*}{ Aviation } & Domestic & Long-dist. & - & - \\
\hline & International & Long-dist. & - & - \\
\hline
\end{tabular}


In this paper, population growth is assumed as the major driver of future passenger travel demand. However, neither demographic development in Malmö, nor differences in travel patterns between age groups are considered (but will be in future studies). When city-specific population growth projections until 2050 is not available, national trends from Statistics Sweden [38] are used and scaled to Malmö. The population growth projections are combined with data from the city's travel survey to derive future by-mode passenger travel demands. For freight transportation, GDP per capita is assumed as the major demand driver. Due to lack of city-specific data on freight flows, some simplifications and assumptions were needed. First, a 'material footprint' approach is applied, based on EU average values for freight attraction per capita by commodity groups [39]. This was scaled to Malmö, using GDP per capita data for Sweden from OECD [40], and combined with population growth projections to generate future intracity by-commodity freight transportation demand. By this approach, freight transport demand increases by more than $150 \%$ until 2050, whereas passenger travel increases by $33 \%$. For passenger travelling, different possible futures were created to reflect different 'system choices'. This is presented in Table 3 . The reference case (REF) uses base-year mode shares, the HighCar case reflects extensive use of private cars, and the ModeShift case reflects progressive mode shifting.

\section{DISCUSSION AND CONCLUSIONS}

In this paper, we have improved transport sector representation within the TIMES-City model, to better capture the urban transport-energy setting. TIMES-City is a comprehensive energy system optimisation model covering supply and demand for energy in any given city. From our analysis, some crucial modelling features were identified; urban transport characteristics, needs and challenges of local governments, and improved demand inputs taking mode shift potentials into account. To better understand how to include this in the TIMES-City framework, we have reviewed traditional transport modelling approaches, and current urban energy system practices and transport sector representation. First, urban transportation is characterised by short average distances and slow average speeds, which makes slow modes more competitive. The share of e.g. public transport and non-motorised modes is larger in urban areas compared to the national scale. Currently, this is not reflected in the TIMES model framework. In TIMES-City, walking and bicycling have been explicitly included, along with LEVs and public transport city ferries. For freight transportation, the

Table 3: Intracity passenger mode shares for different cases.

\begin{tabular}{|l|c|c|c|c|c|c|}
\hline \multirow{2}{*}{ Model Input } & \multicolumn{6}{|c|}{ Scenario } \\
\cline { 2 - 7 } & \multicolumn{2}{|c|}{ REF } & \multicolumn{2}{c|}{ HighCar } & \multicolumn{2}{c|}{ ModeShift } \\
\cline { 2 - 7 } & \% of trips & \% of pkm & \% of trips & \% of pkm & \% of trips & \% of pkm \\
\hline Walk & 14.9 & 1.7 & 13.4 & 1.5 & 16.1 & 2.0 \\
\hline Bicycle & 22.1 & 5.7 & 18.0 & 4.7 & 29.4 & 7.7 \\
\hline Car (intracity) & 30.5 & 8.0 & 39.4 & 10.1 & 12.2 & 3.2 \\
\hline Bus (urban) & 10.6 & 2.8 & 7.2 & 1.9 & 20.3 & 5.3 \\
\hline Car (intercity) & 12.1 & 45.2 & 16.0 & 59.5 & 8.9 & 33.2 \\
\hline Bus (intercity) & 3.1 & 11.6 & 1.8 & 6.5 & 5.1 & 18.9 \\
\hline $\begin{array}{l}\text { Train } \\
\text { (intercity) }\end{array}$ & 6.7 & 25.0 & 4.2 & 15.8 & 8.0 & 29.7 \\
\hline
\end{tabular}


choice of inner-city goods distribution via bicycle or light electric vehicles is included. The model also includes the addition of non-travelling options (e-meetings, e-shopping, etc.), to reflect the possibility of eliminating certain trips. Second, modelling the transport sector in a comprehensive energy system framework provides local governments with insights on longterm system dynamics and interactions between energy end-use sectors. This enables consistent analyses of both city-level and single-sector targets. TIMES-City can be used to analyse the city's own activities, or the entire city area (including firms and residents). The model supports analyses of intracity transportation, long-distance transportation attributed to a specific city, or both. This gives local decision makers flexibility in the scope for analysis, and in exploring different targets for city organisation, single-sectors or overall city-level. Third, TIMES-City satisfies user-defined future demand for passenger and freight transportation. Demands are given for each transport mode separately, i.e. mode shifts are not modelled endogenously. By adopting approaches from the transport modelling realm, detailed demand inputs can be generated and inputted to TIMES-City. Pre-modelling analysis of by-purpose mode shares, or e.g. varying mode shift potentials for different trip purposes, can support deeper context-specific analyses. These efforts combined will contribute to improved overall model realism, and increased policy relevance of model outputs.

\section{ACKNOWLEDGEMENTS}

The model development work for this study was conducted as part of the EU-funded SURECITY project. The financial support is gratefully acknowledged. We also thank the project partnership for valuable support and input in the model development process, and the city of Malmö for providing base-year data.

\section{REFERENCES}

[1] European Commission, Green Paper: Towards a new culture for urban mobility [COM (2007) 551], 2007.

[2] Creutzig, F. et al., Transport: A roadblock to climate change mitigation? Science, 350, pp. 911-912, 2015.

[3] Mayeres, I., Ochelen, S. \& Proost, S., The marginal external costs of urban transport. Transportation Research Part D: Transport and Environment, 1 , pp. 111130, 1996.

[4] Nakamura, K. \& Hayashi, Y., Strategies and instruments for low-carbon urban transport: An international review on trends and effects. Transp. Policy, 29, pp. 264 274, 2013.

[5] Churchman, C.W., The Systems Approach. 1st ed., Dell Publishing: New York, 1968.

[6] Tosato, G.C., Getting Started with the Problem - Defining and Describing the Area of Study. Appendix A in Getting started with TIMES-VEDA, version 2.7, Maurizio Gargiulo, 2009.

[7] SURECITY Project Web Site, Online. http://jpi-urbaneurope.eu/project/surcity/. Accessed on: 29 May 2017.

[8] Loulou, R., Remne, U., Kanudia, A., Lehtila, A. \& Goldstein, G., Documentation for the TIMES Model: Part I, 2005.

[9] Dodds, P.E. \& McDowall, W., Methodologies for representing the road transport sector in energy system models. Int J Hydrogen Energy, 39, pp. 2345-2358, 2014.

[10] Grubler, A. et al., Urban Energy Systems, in Global Energy Assessment - Toward a Sustainable Future, pp. 1307-1400, 2012.

[11] ELTISplus, Guidelines: Developing and Implementing a Sustainable Urban Mobility Plan, 2014. 
[12] May, A.D., Encouraging good practice in the development of Sustainable Urban Mobility Plans. Case Studies on Transport Policy, 3, pp. 3-11, 2015.

[13] European Commission, Keep Europe moving - Sustainable mobility for our continent: Mid-term review of the European Commission's 2001 Transport White Paper [COM (2006) 314], 2006.

[14] Delponte, L., Pittaluga, I. \& Schenone, C.M., Monitoring and evaluation of Sustainable Energy Action Plan: Practice and perspective. Energy Policy, 100, pp. 9-17, 2017.

[15] Covenant of Mayors. How to Develop a Sustainable Energy Action Plan (SEAP) Guidebook: Part 2, 2010.

[16] Leal, V.M.S. \& Azevedo, I., Setting targets for local energy planning: Critical assessment and a new approach. Sustainable Cities and Society, 26, pp. 421-428, 2016.

[17] Keirstead, J. \& Calderon, C., Capturing spatial effects, technology interactions, and uncertainty in urban energy and carbon models: Retrofitting Newcastle as a case-study. Energy Policy, 46, pp. 253-267, 2012.

[18] Keirstead, J., Jennings, M. \& Sivakumar, A. A review of urban energy system models: Approaches, challenges and opportunities. Renewable and Sustainable Energy Reviews, 16, pp. 3847-3866, 2012.

[19] de Jong, G., Daly, A., Pieters, M., Miller, S., Plasmeijer, R. \& Hofman, F., Uncertainty in traffic forecasts: Literature review and new results for the Netherlands. Transportation, 34, pp. 375-395, 2007.

[20] McNally, M.G., The Four-Step Model. Handbook of Transport Modelling, eds D.A. Hensher, K.J. Button, Emerald, Inc., pp. 35-53, 2007.

[21] Boyce, D., Williams, H. Forecasting Urban Travel: Past, Present and Future, Edward Elgar Publishing Ltd: Cheltenham, pp. 1-2, 2015.

[22] de Jong, G., Gunn, H. \& Walker, W., National and international freight transport models: Overview and ideas for further development. Transport Reviews, 24, pp. 103124, 2004.

[23] de Jong, G. et al., The issues in modelling freight transport at the national level. Case Studies on Transport Policy, 4, pp. 13-21, 2016.

[24] Saujot, M., de Lapparent, M., Arnaud, E. \& Prados, E., Making land use-transport models operational tools for planning: From a top-down to an end-user approach. Transp. Policy, 49, pp. 20-29, 2016.

[25] Bhat, C.R., Guo, J., Srinivasan, S. \& Sivakumar, A., Guidebook on Activity-Based Travel Demand Modeling for Planners, pp. 7-9, 2003.

[26] de Jong, G., Vierth, I., Tavasszy, L.A. \& Ben-Akiva, M., Recent developments in national and international freight transport models within Europe, p. 13, 2013.

[27] INSMART Project Web Site, Online. http://www.insmartenergy.com/. Accessed on: 29 May 2017.

[28] Simoes, S. et al., The JRC-EU-TIMES model - Assessing the long-term term role of the SET Plan Energy technologies, p. 49, 2013.

[29] Zhang, H., Chen, W. \& Huang, W., TIMES modelling of transport sector in China and USA: Comparisons from a decarbonization perspective. Appl Energy, 162, pp. 15051514, 2016.

[30] Bahn, O., Marcy, M., Vaillancourt, K. \& Waaub, J., Electrification of the Canadian road transportation sector: A 2050 outlook with TIMES-Canada. Energy Policy, 62, pp. 593-606, 2013.

[31] Yang, C., Yeh, S., Zakerinia, S., Ramea, K. \& McCollum, D., Achieving California's $80 \%$ greenhouse gas reduction target in 2050: Technology, policy and scenario 
analysis using CA-TIMES energy economic systems model. Energy Policy, 77, pp. 118-130, 2015.

[32] Comodi, G., Cioccolanti, L. \& Gargiulo, M.M., Municipal scale scenario: Analysis of an Italian seaside town with MarkAL-TIMES. Energy Policy, 41, pp. 303-315, 2012.

[33] Lind, A. \& Espegren, K., The use of energy system models for analysing the transition to low-carbon cities - The case of Oslo. Energy Strategy Reviews, 15, pp. 44-56, 2017.

[34] Statistics (monthly price statistics). International Energy Agency Web Site, Online. http://www.iea.org/statistics/. Accessed on: 26 May 2017.

[35] Energy Technology Perspectives (ETP): Framework Assumptions. International Energy Agency Web Site, Online. https://www.iea.org/etp/etpmodel/assumptions/. Accessed on: 26 May 2017.

[36] Sweco, Resvanundersökning i Malmö, 2013/2014.

[37] Transport Analysis Web Site, Online.http://www.trafa.se/. Accessed on: 28 Mar. 2017.

[38] Population projections, Statistics Sweden Web Site, Online. http://www.scb.se/en/ finding-statistics/statistics-by-subject-area/population/population-projections/ population-projections/. Accessed on: 1 May 2017.

[39] Giljum, S. et al., Identifying priority areas for European resource politics: a MRIObased material footprint assessment. Journal of Economic Structures, 5, pp. 1-24, 2016.

[40] Gross domestic product (GDP). Organisation for Economic Cooperation and Development (OECD) Web Site, Online. https://data.oecd.org/gdp/gross-domesticproduct-gdp.htm. Accessed on: 1 May 2017. 